\title{
Rancang Bangun Spaced Repetition Software untuk Menghafal Huruf Jepang Menggunakan Algoritma SuperMemo 2 Berbasis iOS
}

\author{
Agustyan Hidayat ${ }^{1}$, Ni Made Satvika Iswari ${ }^{2}$ \\ Fakultas Teknik dan Informatika, Universitas Multimedia Nusantara, Tangerang, Indonesia \\ agustyan@hidayat.web.id \\ satvika@umn.ac.id
}

Diterima 26 April 2018

Disetujui 8 Juni 2018

\begin{abstract}
During the study of another language such as Japanese, the problem that exists is in remembering each of the characters that is used as writing mechanism. This is happened because the difference with Roman characters and the number of character that exist, is far beyond that of alphabet which makes a visual impairment for those used to write in alphabet. There is a traditional way to remember something which is periodically learn or remember the characters and assign a visual image to each of the characters in order to be remembered easily. Spaced repetition is a method that give an interval during a repetition which is mainly used for someone who want to remember something periodically by learning it for a long term periodically. This research discusses the implementation of one of spaced repetition algorithm called SuperMemo 2 and using it along with a flasheard to learn Japanese characters periodically. Software development methodology used is Waterfall Model, because the requirements used to develop the software is clear at the beginning.
\end{abstract}

Index Terms-Flashcard, Japanese Characters, Language Learning, Spaced Repetition Software, SuperMemo

\section{PENDAHULUAN}

Dalam mempelajari sebuah bahasa asing seperti bahasa Jepang, kesulitan yang dihadapi adalah untuk menghafal karakter yang digunakan dalam penulisan. Bahasa jepang sendiri memiliki 2 macam penulisan yang umum digunakan yakni Kana dan Kanji. Kana sendiri terbagi menjadi dua yaitu hiragana yang digunakan untuk kata-kata asli dan katakana yang digunakan untuk kata-kata serapan.

Kanji merupakan karakter cina yang diserap dan digunakan bersamaan dengan Hirgana dan Katakana. Pada tahun 2010 jumlah kanji yang umum digunakan sudah mencapai sekitar 2.136 karakter. Dalam menghafalkan kanji terdapat berbagai macam teknik yang dapat dilakukan dan salah satunya adalah flashcard.

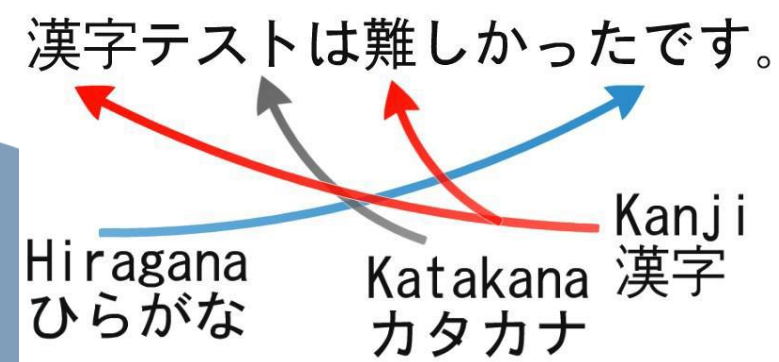

Gambar 1 Contoh Penulisan Bahasa Jepang

Faktor lain yang membuat kanji sulit untuk dihafal adalah sebuah kanji dapat memiliki lebih dari satu arti dan dalam melakukan penulisan kanji terdapat sebuah urutan yang baku. Seperti yang dijelaskan oleh Heisig dalam bukunya yang berjudul "Remembering the Kanji”" pada tahun 2007, hal yang membuat kanji sulit untuk dipelajari adalah kurangnya kesamaan pola pada memori visual seseorang khususnya mereka yang terbiasa menulis menggunakan alphabet [5].

Cara tradisional yang digunakan untuk menghafal sebuah karakter adalah dengan mengulang mempelajari karakter tersebut secara berkala dan menggabungkan visual terhadap kanji tersebut agar dapat lebih mudah mengingat seperti menghubungkan sebuah kanji dengan objek-objek tertentu.

Spaced Repetition merupakan sebuah teknik yang digunakan untuk menghafal sesuatu dengan memberikan jeda yang berubah-ubah pada setiap pengulangan. Pendekatan ini menyerupai cara tradisional yang telah dibahas sebelumnya.

Sebelumnya pernah dilakukan penelitian oleh Jeff Hanks and Ping Zhan dengan judul "The Forgetting Curve and Learning Algorithms" yang membahas tentang algoritma SM-2 dan hasil penggunaanya [6]. Selain itu, Judy Yoneoka dalam paper yang berjudul "A Tailored Intensive Vocabulary Trainer Using an Online Flashcard Site" pada penerapanya digunakan metode Leitner [12]. Namun pada penelitian ini akan dilakukan dengan menggunakan algoritma 
SuperMemo 2 dan dalam bentuk mobile application. Perbedaan Leitner dengan SuperMemo 2 terletak pada bagaimana penentuan jeda pada saat pengulangan (repetition), Metode Leitner hanya menggunakan variabel yang tetap untuk menentukan jeda sedangkan SuperMemo 2 melakukan perhitungan yang dibuat berdasarkan performa dari pengguna. Selain itu, SuperMemo 2 bersifat Open Source sehingga dapat digunakan dan dikembangkan oleh siapa saja.

\section{LANDASAN TEORI}

\section{A. Spaced Repetition Software}

Spaced Repetition Software merupakan sebuah aplikasi yang mengaplikasikan teknik Spaced Repetition yang merupakan sebuah teknik untuk menghafal yang dikembangkan pada tahun 1960. Teknik ini memberikan jeda waktu yang akan terus bertambah pada saat melakukan review pada sebuah informasi yang telah diketahui sebelumnya. Sebuah penelitian yang dilakukan oleh seorang psikolog Jerman, Hermann Ebbinghaus, menjelaskan bahwa ketika seseorang menerima sebuah informasi baru akan segera lupa dalam waktu yang sangat cepat jika tidak memperkuat informasi baru itu dalam ingatan mereka [2]. Berikut merupakan kurva hasil penelitian dari Hermann tentang jangka waktu yang dibutuhkan untuk melupakan sebuah informasi.

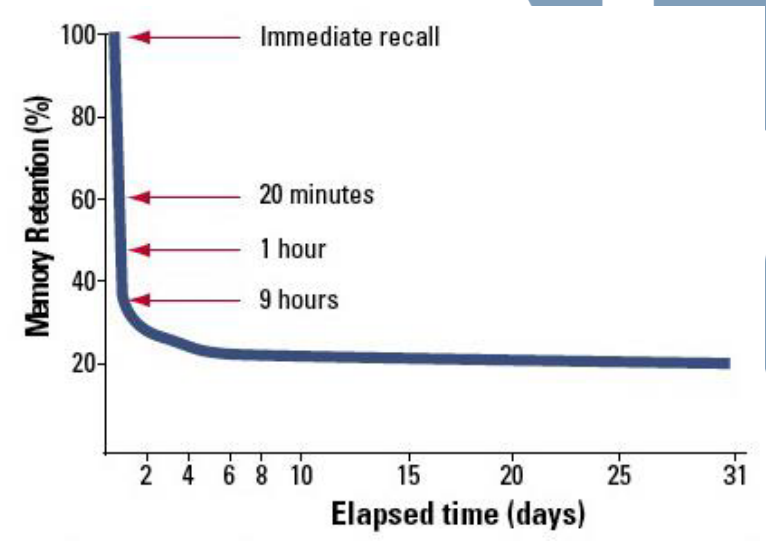

Gambar 2 Forgetting Curve

Dengan memberikan jeda waktu saat melakukan pengingatan terhadap sebuah informasi, maka akan terjadi sebuah spacing effect yang merupakan sebuah istilah psikologi dimana seseorang dapat lebih mudah mempelajari dan mengingat sebuah informasi.

\section{B. Flashcard}

Menurut kamus bahasa Merriam-Webster, Flashcard merupakan sebuah kartu yang memilki kata atau gambar di salah satu atau kedua sisinya. Flashcard dapat digunakan untuk membantu seseorang dalam belajar, khususnya menghafal dengan mengasosiasikan sebuah gambar, kata maupun angka yang digunakan sebagai petunjuk [7].

\section{Joyo Kanji (常用漢字)}

Joyo Kanji yang dapat diartikan sebagai kanji yang digunakan secara umum atau kanji yang biasa dipakai. Joyo Kanji mulai digunakan pada tahun 1981 dan dijadikan standar berdasarkan Pengumuman Kabinet Jepang 1 Oktober. Jumlah kanji yang digunakan awalnya adalah 1945 [8]. Namun pada tahun 2010, total jumlah kanji yang terdapat pada Joyo Kanji ditambahkan hingga mencapai 2.136 karakter yang merupakan gabungan dari 1006 kanji yang diajarkan di sekolah dasar dan 1130 kanji yang diajarkan di sekolah menengah. Joyo Kanji sendiri banyak digunakan di masyarakat, surat kabar, majalah, media elektronik dan sebagainya.

\section{Supermemo 2}

SuperMemo 2 atau disebut juga SM-2 merupakan sebuah algoritma yang dibuat di Polandia oleh Piotr Wozniak [12]. Algoritma ini digunakan untuk memberikan sebuah interval pada sebuah interrepetition.

Di dalam algoritma ini terdapat sebuah variabel yang disebut dengan E-Factor (Easiness Factor). EFactor akan berperan memberikan sebuah nilai pada setiap item yang terdapat pada list. Nilai pada E-Factor memiliki variasi dari 1,1 (Tersulit) hingga 2,5 (Termudah). Untuk mendapatkan E-Factor, pada mulanya nilai E-Factor untuk semua data awal adalah 2,5, selanjutnya digunakan fungsi sebagai berikut [13]

$$
\mathrm{EF}^{\prime}=\mathrm{EF}+(0.1-(5-\mathrm{q}) *(0.08+(5-\mathrm{q}) * 0.02)) \ldots \text { Rumus } 1
$$

dengan q merupakan sebuah variabel yang melambangkan kualitas dari jawaban pada saat menjawab informasi dengan skala 0-5. E-Factor tidak berubah jika $\mathrm{q}<3$.

Selanjutnya perhitungan interval dilakukan dengan fungsi sebagai berikut dengan $\mathrm{n}$ adalah jumlah repetisi pembelajaran [13]

$$
I(1)=1, I(2)=6, I(n):=I(n-1) * E F \ldots \text { Rumus } 2
$$

Nilai dari interval ini akan berubah-ubah seiring dengan repetisi yang dilakukan karena E-Factor akan berubah setiap kali repetisi dilakukan.

\section{E. $\quad$ iOS}

iOS adalah sistem operasi mobile yang dikembangkan oleh Apple. Pada awalnya bernama OS iPhone, namun kemudian diganti dengan iOS pada bulan Juni 2009. iOS saat ini berjalan pada iPhone, iPod touch, dan iPad. Seperti sistem operasi desktop modern, iOS menggunakan antarmuka pengguna grafis, atau GUI. Namun, karena merupakan sistem operasi mobile, iOS dirancang untuk menggunakan input touchscreen, bukan keyboard dan mouse. 


\section{PERANCANGAN SISTEM}

Spaced Repetition Software adalah sebuah sistem yang memanfaatkan algoritma spaced repetition yang digunakan untuk memberikan jeda atau interval pada saat melakukan pembelajaran. Dalam aplikasi ini digunakan flashcard sebagai salah satu metode yang membantu user dalam mempelajari bahasa Jepang dengan algoritma Supermemo 2. Dengan menggunakan aplikasi ini user dapat mengatur flashcard yang ingin dipelajari dan pada saat melakukan pembelajaraan user hanya perlu menjawab sesuai dengan menu yang telah disediakan. Aplikasi akan secara otomatis menghitung jeda pembelajaraan agar dapat terjadi Spacing Effect. Adapun huruf Jepang yang digunakan dalam aplikasi ini adalah Hiragana, Katakana, dan regular-use Kanji (Joyo Kanji) sebanyak 2.136 karakter.

Metodologi pengembangan perangkat lunak yang digunakan adalah Waterfall Model, yang meliputi requirements, design, implementation, verification, dan maintenance. Metode ini dipilih karena requirement yang digunakan untuk mengembangkan perangkat lunak sudah jelas di awal, sehingga tidak perlu ada perubahan lagi.

Spaced Repetition Software ini memiliki dua menu utama, yaitu menu Card List dan menu Learn. Menu Card List digunakan untuk menampilkan data flashcard yang dapat user gunakan untuk dipelajari, sedangkan menu Learn digunakan untuk menampilkan daftar kartu yang telah user pilih dan juga menampilkan flashcard yang harus dipelajari pada saat itu.

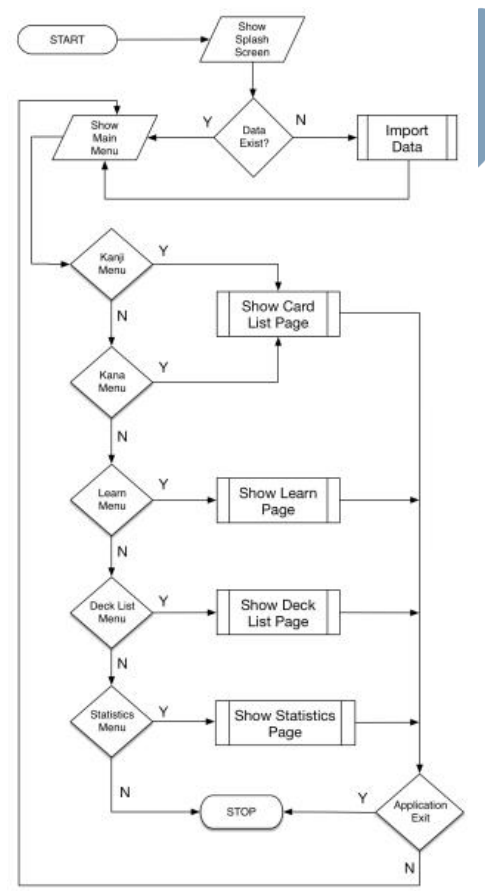

Gambar 3 Diagram Alir Sistem Secara Garis Besar
IV. PENElitian DAN Hasilnya

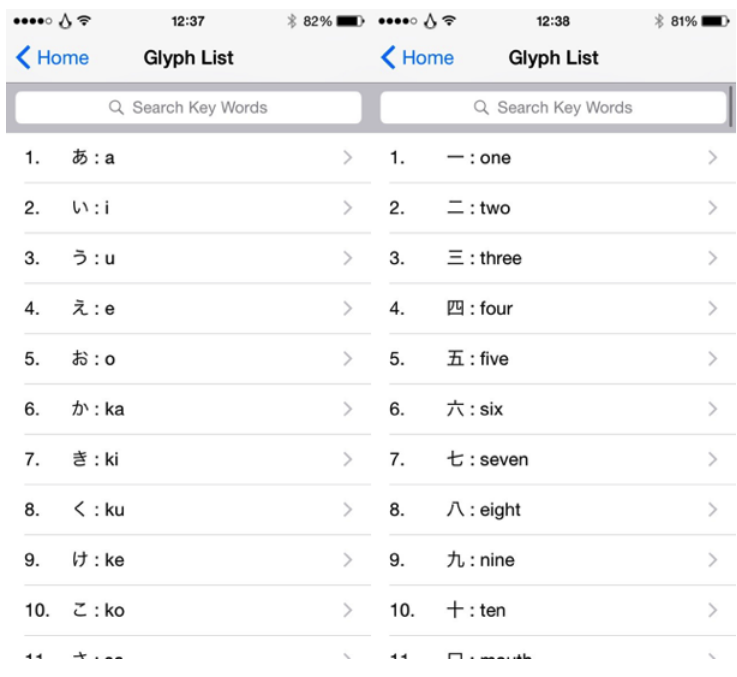

Gambar 4 Tampilan Antarmuka Kana (kiri) dan Kanji (kanan)

Gambar 4 merupakan tampilan antarmuka aplikasi Spaced Repetition Software, saat user menekan tombol pada section card list. Disini user dapat melakukan search terhadap flashcard yang tersedia dan juga dapat melihat detail dari flashcard tersebut dengan melakukan klik pada salah satu item yang terdapat dalam tabel.

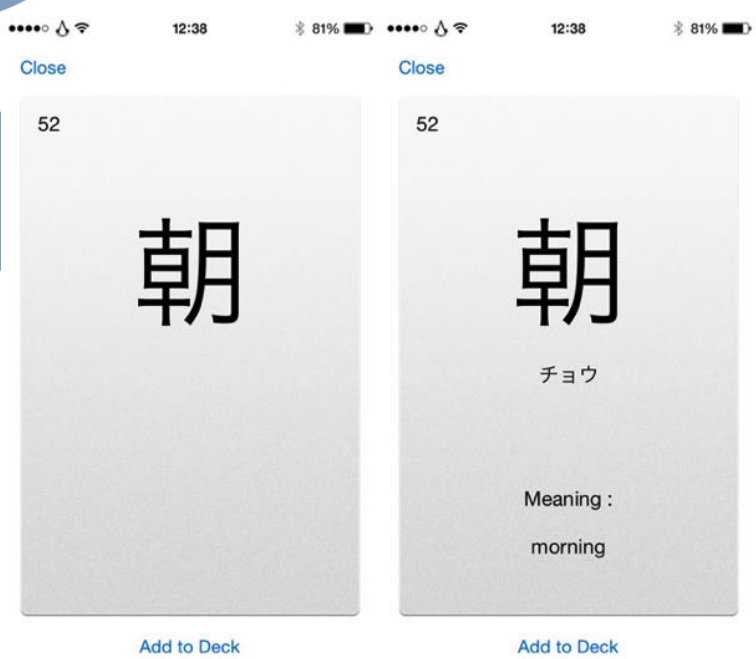

Gambar 5 Tampilan Antarmuka Flashcard Detail Front (kiri) dan Flashcard Detail Back (kanan)

Gambar 5 merupakan tampilan antarmuka aplikasi saat seorang user melakukan pilihan pada salah satu flashcard di menu card list. Aplikasi mengijinkan user untuk melakukan penambahan flashcard ke dalam deck list. Selain itu user juga dapat meilhat detail flashcard dengan melakukan tap pada kartu 
tampilan. Menekan tombol close maupun Add to Deck akan mengembalikan user ke menu Kana atau Kanji.

Di tahap ini, aplikasi yang dibuat diuji apakah sudah berhasil memberikan perhitungan menggunakan algoritma SM-2 dengan tepat, sehingga jeda waktu (Interval) yang dihasilkan sesuai dengan seharusnya sehingga jadwal yang dihasilkan tidak menjadi berantakan. Pengujian dilakukan dengan membandingkan perhitungan secara manual dan membandingkan hasil perhitungan melalui aplikasi yang telah dibangun. Sejumlah skenario perhitungan akan dibuat dimana setiap skenario akan memiliki jumlah iterasi yang berbeda-beda yaitu satu kali, dua kali dan tiga kali iterasi dengan masing-masing skenario memiliki tiga jenis pattern (kombinasi) yang berbeda-beda dan dipilih secara acak. Sebagai contoh pattern q342 berarti user pertama kali menjawab menggunakan button 3 dilanjutkan dengan button 4, dan terakhir dengan button 2.

Metode pengetesan adalah menggunakan debugging button yang dibuat untuk mengemulasikan agar waktu pengetesan adalah hari yang sama ketika tombol tersebut ditekan dengan membuat nilai variabel perbedaan hari yang menjadi counter pembanding bernilai sama dengan nilai variabel Interval yang merupakan hasil perhitungan dari algoritma.

Rumus 1 dan rumus 2 merupakan rumus dasar yang digunakan pada algoritma SM-2. Di dalam rumus tersebut terdapat variabel, seperti $n$ yang merupakan urutan iterasi yang akan bertambah ketika user menjawab pada saat pengetesan secara berkala. Untuk nilai $\mathrm{n}=1$ dan $\mathrm{n}=2$, maka nilai interval yang dihasilkan statis yaitu 1 dan 6 , selanjutnya nilai interval akan menggunakan rumus seperti yang tertera pada rumus 4.1. Setiap kali user menjawab, maka akan dihasilkan variabel q yang merupakan quality (kualitas jawaban) sesuai dengan nilai dari user. Ketika nilai q < 3, maka nilai EF tidak perlu diubah dan interval dikembalikan menjadi satu. Jika nilai $q>2$ maka perhitungan EF dilakukan menggunakan rumus yang tersedia.
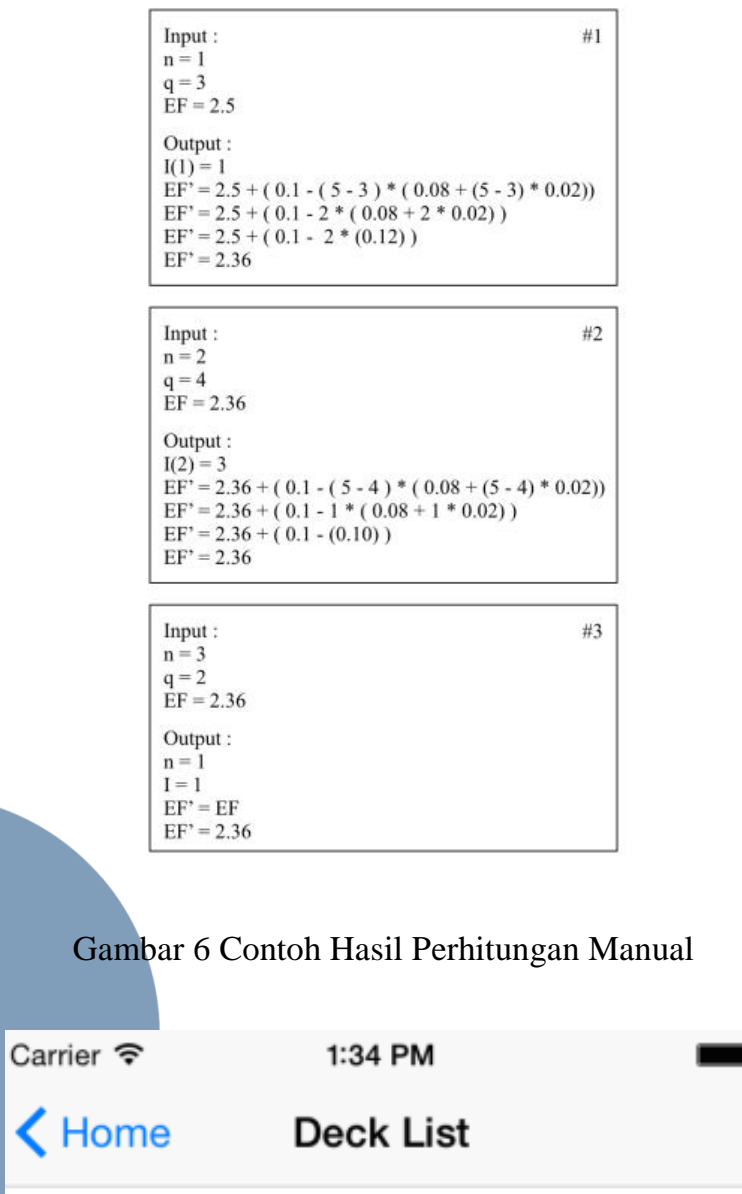

1. 七

n: 1, EF: 2.36, I: 1, DateDiff: 0

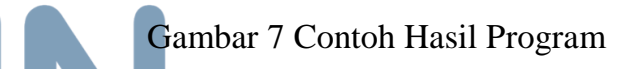

\section{SIMPULAN DAN SARAN}

Simpulan dari penelitian yang dilakukan adalah aplikasi Spaced Repetition Software telah berhasil dibangun dengan mengimplementasikan algoritma SM-2 untuk memberikan inter-repetition dari data flashcard yang diberikan.

Berdasarkan hasil pengujian, algoritma yang digunakan telah berhasil memberikan interval yang dinamis dimana nilai easiness factor yang dihasilkan mempengaruhi besarnya interval yang dihasilkan sehingga jeda pengulangan dapat berubah-ubah menyesuaikan dengan penggunaan dari user.

Saran yang dapat diberikan untuk penelitian selanjutnya, antara lain adalah masih diperlukan pengembangan pada sistem pembelajaran, sehingga user dapat memberikan inputan yang dapat diproses dan diberi nilai yang berupa variabel q atau Quality yang digunakan oleh algoritma SM-2. Sebagai contoh, user diberikan sebuah pilihan ganda atau isian untuk dijawab yang kemudian akan dikonversi menjadi variabel $\mathrm{q}$ dengan metode penilaian tertentu seperti misalnya quiz atau dengan kecepatan menjawab. 
Selain itu, dapat juga ditambahkan sebuah fitur untuk menghafal bagaimana cara penulisan karakter dimana user diminta untuk menulis karakter tersebut di layar dan hasil input dari user akan dicocokan dengan data penulisan yang ada. Selain itu, dapat juga ditambahkan output suara pada flashcard untuk mempelajari cara pengucapan.

\section{DAFTAR PUSTAKA}

[1] Apple. 2014. The Swift Programming Language. Dalam https://itunes.apple. com/us/book/swift-programminglanguage/id881256329?mt=11. Diakses 7 Maret 2015.

[2] Ebbinghaus, H. 2011. Memory: A Contribution to Experimental Psychology. German: Martino Fine Books.

[3] Edge, D., Fitchett, S., Whitney, M., \& Landay, J. 2012. MemReflex: Adaptive Flashcards for Mobile Microlearning. ACM.

[4] Gwern. 2011. Spaced Repetition. Dalam http://www.gwern.net/Spaced\%20repetition. Diakses 15 Maret 2015.

[5] Heisig, J. W. 2007. Remembering the Kanji. Honolulu: University of Hawai'i Press.

[6] Hanks, J., Zhan, P. 2012. The Forgetting Curve and Learning Algorithms.
https://edo.repo.nii.ac.jp/index.php\%3Faction\%3Dpages_view _main\%26active_action\%3Drepository_action_common_down load\%26item_id\%3D9.Diakses 21 Maret 2015.

[7] Merriam-Webster. 2015. Dalam http://www.merriamwebster.com/dictionary/flash\%20card. Diakses 20 Maret 2015.

[8] Seeley, C. 1991. A History of Writing in Japan. BRILL.

[9] SyndeonSoft. The spacing effect. 2012. Dalam http://www.flashcardlearner.com/ articles/the-spacing-effect/. Diakses 15 Maret 2015.

[10] You2. 1998. Comparison of learning systems and programs. Dalam https:// www.you2.de/karteikartensystem/lernprinzipe.html. Diakses 15 Maret 2015.

[11] Yoneoka, J. 2006. A Tailored Intensive Vocabulary Trainer Using an Online Flashcard Site. Dalam http://www2.kumagaku.ac.jp/teacher/ judy/letflash cardspaper.htm. Diakses 21 Maret 2015.

[12] Wozniak, P. 1990. Optimization of learning. Poznan: University of Technology.

[13] Wozniak, P. 1998. Application of a computer to improve the results obtained in working with the SuperMemo method. Dalam http://www.supermemo .com/english/ol/sm2.htm. Diakses 21 Maret 2015.

[14] Inet. 2016. iOS. Dalam https://www.informasiinternet.com/2016/12/ios.html. Diakses 21 Mei 2018.

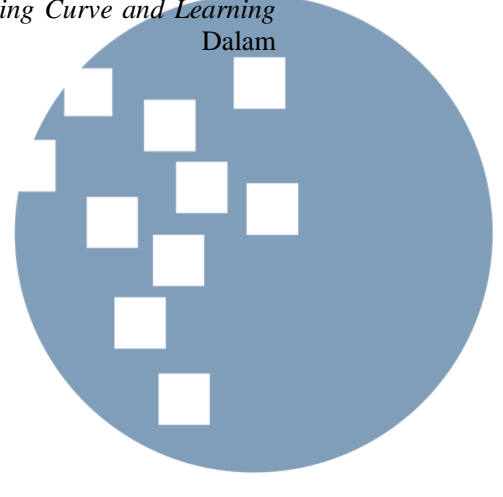

